\title{
International Comparison of High-Technology Manufacturing and Knowledge-Intensive Services in the EU
}

\author{
Astra Auziṇa-Emsina, Riga Technical University
}

\begin{abstract}
High-technology industries that apply the most advanced and cutting edge technologies are frequently analysed as an opposite to low-technology industries. Following a similar approach, services are subdivided by knowledge-intensity into two major dichotomic groups: knowledge-intensive services and less knowledge-intensive services. The aim of the research is to evaluate how these industries perform in reality, whether these industries have the largest value added and highest efficiency and productivity level as it is believed by theory and various policy documents.
\end{abstract}

Keywords - High-technology industry, knowledge-intensive services, manufacturing, input-output.

\section{INTRODUCTION}

The importance of high-technologies and application in any EU economy are strongly encouraged by various types of means. The leading economic policy document of the EU, Europe 2020 (by European Commission (2010)), sets ten quantity targets that should be achieved by all member states in 2020. One target is directly focused on the necessity to stimulate research and development $(R \& D)$ and innovation in the economy, combined with more efficient use of resources, which results in more competitive economy and also creates new jobs. This target states that $3 \%$ of the EU's GDP should be invested in R\&D. The latest statistics of 2012 by Eurostat (2014d) indicates that on average only $2.07 \%$ was invested in R\&D. At the moment, only three countries out of $28 \mathrm{EU}$ countries have the R\&D in GDP (\%) close to 3\%: Denmark (2.98\%), Germany (2.98\%), and Austria (2.84\%). At the same time, many EU countries have a long way to go to reach the target level in time due to the fact that the current level is relatively low. Such countries are Cyprus (0.46\%), Romania $(0.49 \%)$, Latvia $(0.66 \%)$, Greece $(0.69 \%)$ and Croatia $(0.75 \%)$. Europe 2020 clearly declares the urge to improve the investment in R\&D by both public institutions and companies and stresses that there is a clear need to improve the conditions for private $R \& D$ in the EU and it is believed that many of the measures proposed in Europe 2020 strategy will do this.

Several studies are devoted to the fact that many countries will have problems or even fail to reach the target level in 2020, e.g., the study of Else (2014) that analyses the case of Great Britain and selected EU countries Finland, Sweden and Denmark, the study of Duguleană \& Duguleană (2011) that subdivides the EU countries into 4 groups by R\&D in GDP (\%) and average growth rate of R\&D in GDP (\%): Leaders, Followers, Catching-Up, and Trailing. Hence, we can say that this is not a new issue and there are several ways presented of how to deal with it. The literature review reveals the fact that many studies are mainly devoted to one certain country or a narrow sample of countries is analysed; there are not so many general studies that cover all EU countries using common research methodology.

As target indicator of R\&D in GDP (\%) has also been discussed and criticized that is too general and cannot characterize investment efficiency and innovation intensity. Several studies and reports hence include such additional indicators as investment in R\&D per capita (in Euro). However, at the moment European Commission (2010) proposes to keep the target indicator and its 3\% target while developing an indicator which would reflect R\&D and innovation intensity and hence eliminate the drawbacks of current target indicator.

High-technology manufacturing industries that apply most advanced and cutting edge technologies are frequently analysed as an opposite to low-technology industries. It is believed that high-technology and medium-high technology industries are the main drivers of the EU's industrial growth and hence these industries have an utmost importance in the economy.

Following a similar approach, services are subdivided by knowledge-intensity into two major dichotomic groups: knowledge-intensive services and less knowledge-intensive services. Both classifications regarding manufacturing and service sector are clearly stated and applied by Eurostat.

The issues related to high-tech knowledge-intensive services and their impact on economy are analysed mostly from a slightly different point of view. Several authors who study the problems related to the techniques and solutions of how to measure the innovation activity in knowledge-intensive services, rely on the data obtained in large sample surveys (Gotsch \& Hipp, 2012; Shearmur \& Doloreux, 2013). Many authors who studied these issues argue that services and especially knowledge-intensive services are typically extremely heterogeneous and thus difficult to analyse (Ritala, Hyötylä, Blomqvist \& Kosonen, 2013). The literature review indicates that in various studies different methods and approaches are applied.

The paper is devoted to the statistical analysis of industries and services that are classified as high-technology industries and knowledge-intensive services. The aim of the research is to evaluate how these industries perform in reality in the EU, whether these industries have the largest share of value added 
per unit of output and highest efficiency and productivity level as it is believed by theory and various policy documents.

Linking the research results of the analysis of hightechnology manufacturing industries and knowledge-intensive services gives valuable information for policy makers all over the world, for example, in the situation to answer the following question: whether investments should be stimulated in certain industries or, on the contrary, in all industries to gain larger effect and improvement of national and EU economic performance and global competitiveness. The research contains findings that might be a valuable resource of information for government economic and structural policy makers, as well for businesses.

\section{Methodology OF RESEARCH}

Regarding the statistics within the EU, Eurostat applies an explicit aggregation of the manufacturing industry (Jaegers et al., 2013) and services by technology or knowledge intensity that are based on NACE Rev. 2 at 2-digit and 3-digit level. Manufacturing industry is subdivided into:
1) high-technology industry,
2) medium-high-technology industry,
3) medium-low-technology industry,
4) low-technology industry.

Services are subdivided into:

1) knowledge-intensive services,

2) less knowledge-intensive services.

In the research, aggregations based on NACE Rev. 2 at 2-digit level are used. Hence, the following manufacturing industries that are classified as high-technology manufacturing are analysed:

1) Manufacture of basic pharmaceutical products and pharmaceutical preparations (NACE code in parenthesis: C21);

2) Manufacture of computer, electronic and optical products $(\mathrm{C} 26)$.

And the following services that are classified as high-tech knowledge-intensive services are analysed:

1) Motion picture, video and television programme production; programming and broadcasting activities (J59_J60),

2) Telecommunications (J61)

3) Computer programming, consultancy, and information service activities (J62_J63).

Some studies apply the previous NACE revision (Rev1.1) (as Vence-Deza \& González-López, 2008), these findings can be used as indicative but due to the differences in classification these results cannot be directly applied in practice.

The shares of value added in output (v) of industry $j$ (or value added per unit of output) in a country $c$ at the time period $t$ are computed as the ratios of value added of industry $j$ in a country $c$ at the time period $t$ to the output of industry $j$ in a country $c$ at the time period $t(1)$ :

$$
v_{j, c, y}=\frac{V A_{j, c, y}}{O U T_{j, c, y}}
$$

Theoretically, the indicator $v$ can have values from 0 to 1 ; in practice indicator $v$ should not have values close to the extreme points of interval - close to 0 and close to 1 .

In addition, a country's shares in total value added of the analysed industry (\%) are computed by (2) in order to detect the leading countries, as well as to analyse the relations between the indicators $\mathrm{v}$ and $\mathrm{sh}$.

$$
s h_{j, c, y}=\frac{V A_{j, c, y}}{\sum V A_{j, c, y}}
$$

The indicator sh represents a share of certain element in the total value, hence the values of indicator sh can have values from 0 to 1 or from $0 \%$ to $100 \%$. In practice, indicator sh does not have values close to extreme points of interval - close to 0 (or $0 \%$ ) and close to 1 (or $100 \%$ ) as manufacture of certain high-tech products or services takes place in many (or at least in several) countries and there is not one monopolistic country that holds $100 \%$ share of the certain market.

In the computation, the Eurostat input-output data (national use tables at current prices in euros) of 2010 of all EU member states are used as very detailed and specific sectoral data are required. The study does no cover Denmark, Spain, Cyprus, Luxembourg and Malta due to the data non-availability (no appropriate input-output data available) and non-comparability to the majority of countries covered. This is technical rather than geographical limitation, hence we can say that the study covers all EU countries that provide the required data.

\section{RESULTS}

Despite the mainstream confidence that high-technology industries add greater value added in production process in comparison to medium- and low-technology industries, the results claim that it can be observed only in certain hightechnology industries and/or in certain countries due to the production traditions and technologies applied.

The share of value added in manufacture of basic pharmaceutical products and pharmaceutical preparations on average in the analysed EU countries is 0.39 . At the same time in three countries that are the leading producers of pharmaceutical products in the EU: Germany (accounts for $23 \%$ of total production) -0.46 ; the UK $(21 \%)-0.57$, and Ireland $(17 \%)-0.34$. The highest shares of value added in output are observed in Lithuania - 0.82; Finland - 0.64, and Greece - 0.59, but these countries account for only, respectively, $0 \%, 1 \%$ and $1 \%$ of production (see Fig. 1). However, the interval of national values is relatively huge $(0.11-0.82)$. 


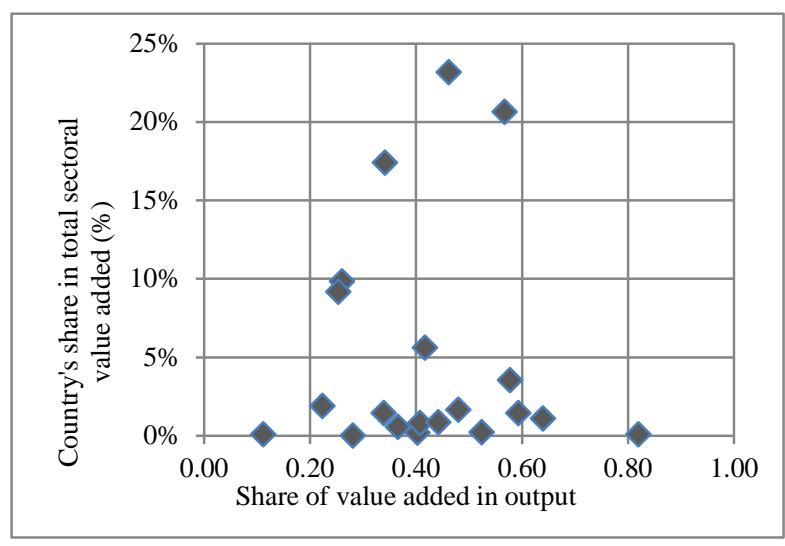

Fig. 1. Manufacture of basic pharmaceutical products and its preparations in the EU in 2010.

The manufacture of computer, electronic and optical products is relatively a low value added industry in reality in the EU, despite the fact that this industry is included in the high-technology group by official classification. The average share of value added in output is only 0.30 in the EU. It is observed that the indicator strongly varies among countries (Fig.2). This industry is specific due to fact that one country has a significantly large share in total production - Germany which is the leading producer (accounts for 34\% of total production); the indicator $\mathrm{v}$ is 0.40 that is above the sectoral average level. At the same time, several countries show very high indicator v values (Romania - 0.69 and Greece - 0.59), but these countries have relatively tiny market share; respectively $-3 \%$ and $0 \%$. It is also visible that the interval of national values is relatively huge $(0.08-0.69)$.

The low value of 0.08 (in Hungary) is rationally hard to understand; nevertheless, manufacture of computer, electronic and optical products is a very diverse economic activity and it can include either just the assembly activities or a full production process. In order to give clear recommendations for Hungary economy regarding this industry, further more detailed research is required.

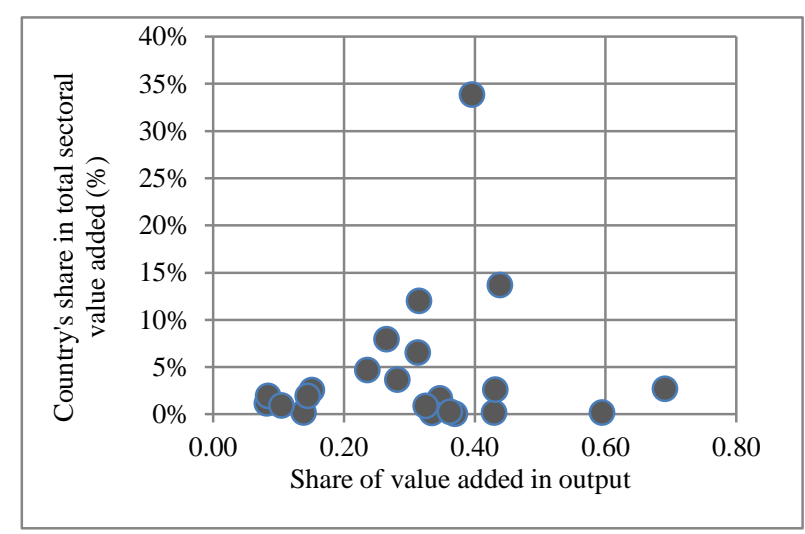

Fig. 2. Manufacture of computer, electronic and optical products in the EU in 2010.
High-tech knowledge-intensive services indicate relatively high values of indicator $\mathrm{v}$ in the EU. The EU's motion picture, video and television programme production, including programming and broadcasting activities are mostly located in five countries - the UK, Germany, Italy, France, and Ireland, that respectively accounts for $23 \%, 19 \%, 16 \%, 15 \%$, and $9 \%$ of the market. The values of indicator $\mathrm{v}$ noticeably vary in these leading countries, and are the following: Italy -0.54 , the UK -0.51 , Germany -0.42 , Ireland -0.38 , and France -0.37 . Other EU countries have a relatively small market share and even larger interval of values (see Fig.3).

It is also noticeable that the interval of national values is relatively narrow $(0.28-0.54)$ if compared to other economic activities analysed in the study.

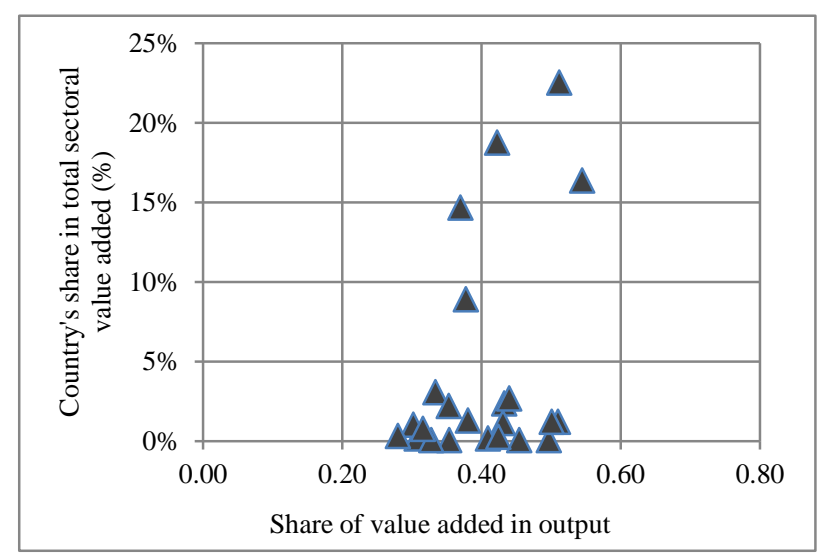

Fig. 3. Motion picture, video and television programme production, including programming and broadcasting activities in the EU in 2010.

Telecommunications as high-tech knowledge-intensive service activity has higher values of indicator $\mathrm{v}$ than the previously-analysed motion picture et al. activities -0.46 . There are four leading countries in this economic activity France, the UK, Italy, and Germany, that respectively accounts for $19 \%, 18 \%, 16 \%$, and $15 \%$ of the market. The values of indicator $\mathrm{v}$ noticeably vary in these leading countries, and are the following: France -0.44 , the UK -0.50 , Italy -0.50 , and Germany -0.38 . Other EU countries have relatively small market share and even larger interval of values (0.35-0.66) (Fig. 4).

In the study, it is detected that the interval of national values of this activity (like motion picture, video and television programme production, including programming and broadcasting activities) is relatively narrow (0.35-0.66) if compared to other analysed economic activities. Only these two economic activities out of five economic activities analysed show such results while other economic activities demonstrate very wide variations caused by different factors. 


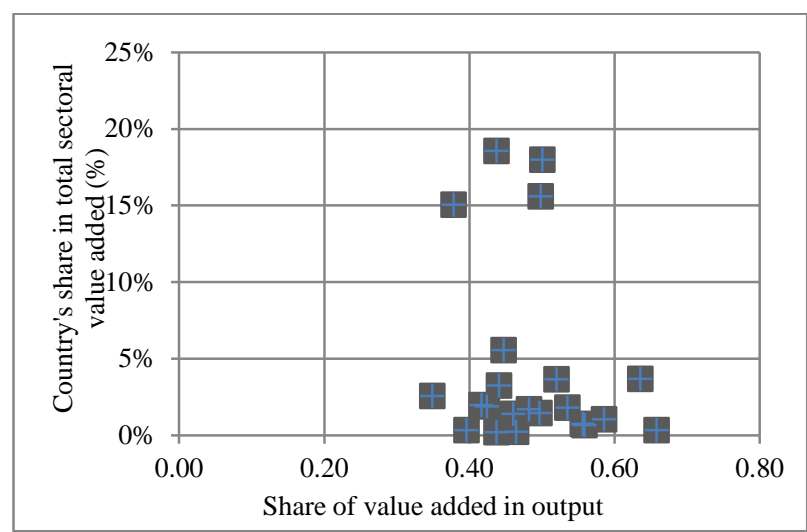

Fig. 4. Telecommunications in the EU in 2010.

Computer programming, consultancy, and information service activities show the largest value added share in output unit - on average 0.55. It is the highest value amid all analysed high-tech activities covered in this research. In this economic activity in the EU, four countries hold leading position: the UK, France, Germany, and Italy, that respectively accounts for $23 \%, 20 \%, 19 \%$, and $12 \%$ of the market. The values of indicator $\mathrm{v}$ are relatively close in these leading countries, and are the following: the UK -0.62 , France -0.60 , Germany -0.61 , and Italy -0.52 . Other EU countries have a relatively small market share and even larger interval of values $(0.19-0.65)$ (see Fig. 5).

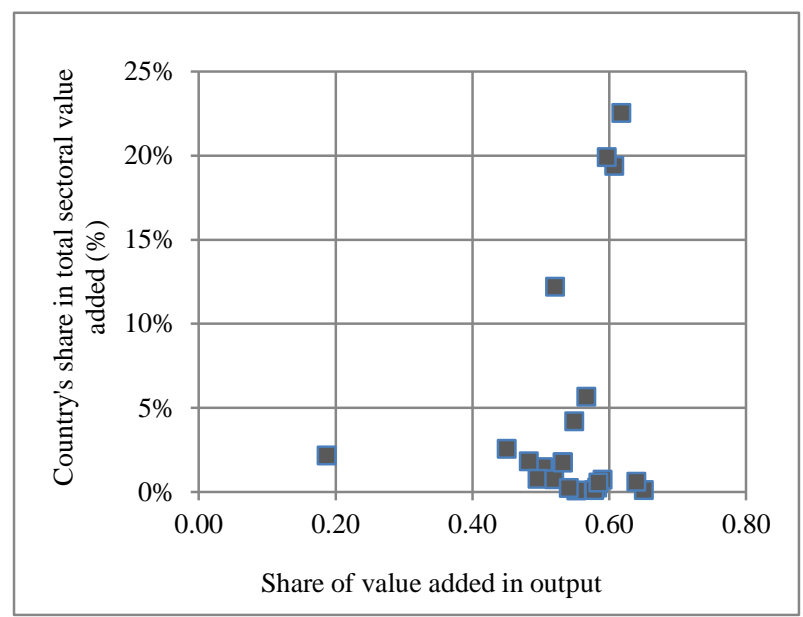

Fig. 5. Computer programming, consultancy, and information service activities in the EU in 2010.

The performed analysis gives the ground to argue that hightech knowledge-intensive services indicate higher values of indicator $\mathrm{v}$ than high-tech manufacturing industries (Table I). In other words, relatively higher value added is generated in the production process of the above-stated service activities. It results in the fact, that one unit of output generates larger value added, hence this activity is more efficient and productive.

A more detailed research of data at national level gives the ground to argue that applied technologies, materials, historical sectoral development, traditions, etc., are very diverse and have a huge influence on actual structure and performance of economic activity. And hence the productivity of high-tech economic activities significantly varies amid EU countries.

\section{TABLE I}

VALUES OF INDICATOR V IN HIGH-TECH MANUFACTURING INDUSTRIES AND HIGH-TECH KNOWLEDGE-INTENSIVE SERVICES IN THE EU IN 2010

\begin{tabular}{|l|l|c|}
\hline \multicolumn{1}{|c|}{ Sector } & \multicolumn{1}{|c|}{ Industry/Activity } & Value \\
\hline $\begin{array}{l}\text { High-tech } \\
\text { manufacturing }\end{array}$ & $\begin{array}{l}\text { Manufacture of basic pharmaceutical } \\
\text { products and its preparation (C21) }\end{array}$ & 0.39 \\
\cline { 2 - 3 } & $\begin{array}{l}\text { Manufacture of computer, electronic } \\
\text { and optical products (C26) }\end{array}$ & 0.30 \\
\hline $\begin{array}{l}\text { High-tech } \\
\text { knowledge- } \\
\text { intensive } \\
\text { services }\end{array}$ & $\begin{array}{l}\text { Motion picture, video and television } \\
\text { programme production; programming } \\
\text { and broadcasting activities (J59_J60), }\end{array}$ & 0.43 \\
\cline { 2 - 3 } & \begin{tabular}{l} 
Telecommunications (J61) \\
\cline { 2 - 3 }
\end{tabular} & $\begin{array}{l}\text { Computer programming, } \\
\text { consultancy, and information service } \\
\text { activities (J62_J63). }\end{array}$ \\
\hline
\end{tabular}

The countries that have the highest values in most cases perform far better than average level - even more than double in comparison with the average level (Table II). Three countries with the highest values for each high-tech economic activity are presented and the value indicates the value added per unit of output.

TABLE II

THREE EU COUNTRIES WITH THE HighEST VALUES OF INDICATOR $V$ IN High-TeCh Manufacturing INDUSTRIES AND HigH-TeCH KNOWLEDGEINTENSIVE SERVICES IN 2010

\begin{tabular}{|l|l|c|}
\hline \multicolumn{1}{|c|}{ Industry/Activity } & \multicolumn{1}{|c|}{ Country } & Value \\
\hline \multirow{2}{*}{$\begin{array}{l}\text { Manufacture of basic } \\
\text { pharmaceutical products and its } \\
\text { preparation (C21) }\end{array}$} & Lithuania & 0.82 \\
\cline { 2 - 3 } & Finland & 0.64 \\
\cline { 2 - 3 } & Greece & 0.59 \\
\hline $\begin{array}{l}\text { Manufacture of computer, electronic } \\
\text { and optical products (C26) }\end{array}$ & Romania & 0.69 \\
\cline { 2 - 3 } & Greece & 0.59 \\
\cline { 2 - 3 } & UK & 0.44 \\
\hline \multirow{2}{*}{$\begin{array}{l}\text { Motion picture, video and television } \\
\text { programme production; } \\
\text { programming and broadcasting } \\
\text { activities (J59_J60), }\end{array}$} & Italy & 0.54 \\
\cline { 2 - 3 } & Hungary & 0.51 \\
\cline { 2 - 3 } & UK & 0.51 \\
\hline Telecommunications (J61) & & 0.62 \\
\hline \multirow{2}{*}{$\begin{array}{l}\text { Computer programming, } \\
\text { activities (J62_J63). }\end{array}$} & Lithuania & 0.66 \\
\cline { 2 - 3 } & Greece & 0.64 \\
\cline { 2 - 3 } & Hungary & 0.59 \\
\cline { 2 - 3 } & Greece & 0.65 \\
\cline { 2 - 3 } & UK & \\
\hline
\end{tabular}

It should be stressed that these countries have very diverse size of their economies and size of certain market in respect to industry's total market. However, several countries can be found as leaders in several economic activities presented in Table II, for example, the UK, Greece, Lithuania and Hungary. 


\section{DISCUSSION AND CONCLUSION}

The research results claim that only certain high-technology industries add greater value added per unit of output (indicator v) and it takes place only in certain countries. In the study, no evidence was found that there exists a pan-EU hightechnology industry or high-tech knowledge-intensive sector that has evenly high performance in all EU countries. Hence, the research results argue that economic activities that are classified as high-tech activities (for example, for needs of statistics on the basis of NACE rev.2) can give high results in some countries and contrariwise, weak results, in other countries. It is recommended for national and EU policy makers to analyse each industry and each country separately as none of the industries can be undertaken without doubts as truly high-tech sectors that should be hence stimulated in the economy. It should be stressed that the aim of the research is to evaluate how these industries perform in reality in the EU (relying on the official statistical data and analysis) and whether these industries have the largest value added and highest efficiency and productivity level as it is believed by theory and various policy documents. The study does not cover causality issues or historical (including technological) developments that are significant elements but are out of the scope of this research.

The research findings indicate a clear example of such a dual situation. Manufacture of computer, electronic and optical products, which is classified as high-technology manufacturing, performs on average poorly and the values of indicator $\mathrm{v}$ are relatively low (even lower than the average of total economy).

These findings raise several questions, firstly, whether statistical methodology is applied correctly in all EU countries; secondly, whether certain economic activities that are believed to be a part of manufacture of computer, electronic and optical products should be redistributed and moved to other and more appropriate group; thirdly, why certain countries have so high performance but some have so poor results or whether there are some technological and labour (availability, skills etc.) restrictions that should definitely be taken into account.

And it is concluded that the EU high-tech knowledgeintensive services add larger value added per unit of output than high-tech manufacturing industries. It gives strong ground to argue that investments in R\&D is a powerful tool that can boost certain industries, hence it should be considered to be placed also in theses service activities. The results encourage making investments in $R \& D$ in more efficient economic activities, some of them definitely are high-tech, in order to have larger economic effect afterwards (investment multiplier effect).

The findings might be a valuable resource of entry-level information for government economic and structural policy makers in national and EU institutions in order to have an insight in certain sectors, as well as for the applied business analysis in the EU companies that allocate the resources and capital in various countries.

\section{REFERENCES}

Duguleană, L. L., \& Duguleană, C. C. (2011). Dynamics of R\&D Expenditure in Europe During the Last Two Decades. Bulletin Of The Transilvania University Of Brasov. Series V: Economic Sciences, $4(2), 147-152$.

Else, H. (2014). Falling Short: R\&D Investment Fails to Reach Europe 2020 Targets. Times Higher Education, (2157), 9.

European Commission (2010). Europe 2020. A strategy for smart, sustainable and inclusive growth. Retrieved from http://ec.europa.eu/europe2020/ documents/related-document-type/index_en.htm

Eurostat (2014a). Supply, use and Input-output tables. Retrieved from http://epp.eurostat.ec.europa.eu/portal/page/portal/statistics/search_data base

Eurostat (2014b). Aggregations of manufacturing based on NACE Rev.2. Retrieved from http://epp.eurostat.ec.europa.eu/cache/ITY_SDDS/ Annexes/htec_esms_an3.pdf

Eurostat (2014c). High-tech industry and knowledge-intensive services. Retrieved from http://epp.eurostat.ec.europa.eu/cache/ITY_SDDS/ en/htec_esms.htm

Eurostat (2014d). Europe 2020 indicators. Retrieved from http://epp.eurostat.ec.europa.eu/portal/page/portal/europe_2020_indic ators/headline_indicators

Gotsch, M., \& Hipp, C. (2012). Measurement of innovation activities in the knowledge-intensive services industry: a trademark approach. Service Industries Journal, 32(13), 2167-2184. http://dx.doi.org/10.1080/02642069.2011.574275

Jaegers, T., Lipp-Lingua, C., Amil, D. (2013). High-technology versus lowtechnology manufacturing. Retrieved from http://epp.eurostat.ec.europa.eu/statistics_explained/index.php/Hightechnology_versus_low-technology_manufacturing.

Ritala, P., Hyötylä, M., Blomqvist, K., \& Kosonen, M. (2013). Key capabilities in knowledge-intensive service business. Service Industries Journal, 33(5), 486-500. http://dx.doi.org/10.1080/02642069.2011.623774

Shearmur, R., \& Doloreux, D. (2013). Innovation and knowledge-intensive business service: the contribution of knowledge-intensive business service to innovation in manufacturing establishments. Economics $O f$ Innovation \& New Technology, 22(8), 751-774. http://dx.doi.org/10.1080/10438599.2013.786581

Vence-Deza, X. X., \& González-López, M. M. (2008). Regional Concentration of the Knowledge-based Economy in the EU: Towards a Renewed Oligocentric Model?. European Planning Studies, 16(4), 557-578. http://dx.doi.org/10.1080/09654310801983472

Astra Auziņa-Emsina received the PhD degree in economics (Dr. oec.) from Riga Technical University in 2008.

Since 2006 she has been a Researcher and since 2009 an Associate Professor with the Faculty of Engineering Economics and Management of Riga Technical University. She has been involved in research devoted to economic modelling and sectoral interlinkages since 2004 and has developed several multi-sectoral macroeconomic models (INFORUM type model and CGE models for Latvia's economy). Her special research interests are the following: macroeconomic modelling, input-output, inter-sectoral relations, industrial development, economic development, productivity and competitiveness.

She is a member and co-founder of the Association of Latvian Young Scientists, member of the International Input-Output Association and the Association of Latvian Econometrists.

Address: 6 Kalnciema Str., Room 216, Riga LV-1048, Latvia.

E-mail: astra.auzina-emsina @ rtu.lv 